\title{
Rev-erb-alpha modulates skeletal muscle oxidative capacity by regulating mitochondrial biogenesis and autophagy
}

Citation for published version (APA):

Woldt, E., Sebti, Y., Solt, L. A., Duhem, C., Lancel, S., Eeckhoute, J., Hesselink, M. K. C., Paquet, C., Delhaye, S., Shin, Y., Kamenecka, T. M., Schaart, G., Lefebvre, P., Neviere, R., Burris, T. P., Schrauwen, P., Staels, B., \& Duez, H. (2013). Rev-erb-alpha modulates skeletal muscle oxidative capacity by regulating mitochondrial biogenesis and autophagy. Nature Medicine, 19(8), 1039-1046. https://doi.org/10.1038/nm.3213

Document status and date:

Published: 01/01/2013

DOI:

10.1038/nm.3213

Document Version:

Publisher's PDF, also known as Version of record

\section{Document license:}

Taverne

Please check the document version of this publication:

- A submitted manuscript is the version of the article upon submission and before peer-review. There can be important differences between the submitted version and the official published version of record.

People interested in the research are advised to contact the author for the final version of the publication, or visit the DOI to the publisher's website.

- The final author version and the galley proof are versions of the publication after peer review.

- The final published version features the final layout of the paper including the volume, issue and page numbers.

Link to publication

\footnotetext{
General rights rights.

- You may freely distribute the URL identifying the publication in the public portal. please follow below link for the End User Agreement:

www.umlib.nl/taverne-license

Take down policy

If you believe that this document breaches copyright please contact us at:

repository@maastrichtuniversity.nl

providing details and we will investigate your claim.
}

Copyright and moral rights for the publications made accessible in the public portal are retained by the authors and/or other copyright owners and it is a condition of accessing publications that users recognise and abide by the legal requirements associated with these

- Users may download and print one copy of any publication from the public portal for the purpose of private study or research.

- You may not further distribute the material or use it for any profit-making activity or commercial gain

If the publication is distributed under the terms of Article $25 \mathrm{fa}$ of the Dutch Copyright Act, indicated by the "Taverne" license above, 


\title{
Rev-erb- $\alpha$ modulates skeletal muscle oxidative capacity by regulating mitochondrial biogenesis and autophagy
}

\author{
Estelle Woldt ${ }^{1-5,9}$, Yasmine Sebti ${ }^{1-5,9}$, Laura A Solt ${ }^{6}$, Christian Duhem ${ }^{1-5}$, Steve Lancel ${ }^{4,7}$, Jérôme Eeckhoute ${ }^{1-5}$, \\ Matthijs K C Hesselink ${ }^{8}$, Charlotte Paquet ${ }^{1-5}$, Stéphane Delhaye ${ }^{1-5}$, Youseung Shin ${ }^{6}$, Theodore M Kamenecka ${ }^{6}$, \\ Gert Schaart $^{8}$, Philippe Lefebvre ${ }^{1-5}$, Rémi Nevière ${ }^{4,7}$, Thomas P Burris ${ }^{6}$, Patrick Schrauwen ${ }^{8}$, Bart Staels ${ }^{1-5} \&$ \\ Hélène Duez ${ }^{1-5}$
}

\begin{abstract}
The nuclear receptor Rev-erb- $\alpha$ modulates hepatic lipid and glucose metabolism, adipogenesis and the inflammatory response in macrophages. We show here that Rev-erb- $\alpha$ is highly expressed in oxidative skeletal muscle and that its deficiency in muscle leads to reduced mitochondrial content and oxidative function, as well as upregulation of autophagy. These cellular effects resulted in both impaired mitochondrial biogenesis and increased clearance of this organelle, leading to compromised exercise capacity. On a molecular level, Rev-erb- $\alpha$ deficiency resulted in deactivation of the Lkb1-Ampk-Sirt1-Ppargc-1 $\alpha$ signaling pathway. These effects were recapitulated in isolated fibers and in muscle cells after knockdown of the gene encoding Rev-erb- $\alpha$, Nr1d1. In complementary experiments, Rev-erb- $\alpha$ overexpression in vitro increased the number of mitochondria and improved respiratory capacity, whereas muscle overexpression or pharmacological activation of Rev-erb- $\alpha$ in vivo increased exercise capacity. This study identifies Rev-erb- $\alpha$ as a pharmacological target that improves muscle oxidative function by modulating gene networks controlling mitochondrial number and function.
\end{abstract}

Skeletal muscle contractility is important for locomotion and posture, activities performed by different myofiber types with distinct contractile and metabolic properties. Mitochondria serve a crucial function in the maintenance of skeletal myofiber homeostasis and matching energy production with demand. They do so through oxidation of glucose-derived pyruvate and $\beta$-oxidation of fatty acids, generating an electrochemical proton gradient through the respiratory complexes of the electron transport chain; this gradient can be used to drive the phosphorylation of ADP to ATP, a reaction called oxidative phosphorylation (OXPHOS). However, what determines mitochondrial content and function is not completely understood.

Nuclear receptors and their cofactors regulate metabolism in response to environmental signals and trigger homeostatic responses by coordinately regulating transcriptional networks. Previous studies have established that nuclear receptors, such as peroxisome proliferator-activated receptor- $\beta / \delta$ (Ppar- $\beta / \delta)$, estrogen-related receptor- $\alpha$ and estrogen-related receptor- $\gamma$, along with co-regulators such as Ppar- $\gamma$ coactivator- $1 \alpha$ (Ppargc- $1 \alpha)$ and Ppargc- $1 \beta$, as well as nuclear receptor co-repressor 1 (Ncor1), among others, control muscle physiology by modulating mitochondrial biogenesis and function, fiber type determination and switching and muscle vascularization ${ }^{1-5}$. Ppargc- $1 \alpha$ is a master driver of mitochondrial biogenesis, and its overexpression in skeletal muscle results in increased mitochondrial number and function ${ }^{1}$, whereas skeletal muscle Ppargc- $1 \alpha$ deficiency leads to a reduced number of mitochondria and a marked reduction of muscle oxidative capacity ${ }^{6,7}$.

The nuclear receptor Rev-erb- $\alpha$ is expressed in tissues such as liver and adipose tissue ${ }^{8}$, where it modulates lipid, bile acid and glucose metabolism ${ }^{8-13}$. In addition, Rev-erb- $\alpha$ controls adipogenesis $^{14,15}$ and the macrophage inflammatory response ${ }^{16}$. Rev-erb- $\alpha$ interacts with Ncor1 and chromatin modifiers, such as histone deacetylase 3 , to form a complex repressing target gene transcription ${ }^{17}$. Notably, a Rev-erb- $\alpha$-Ppargc- $1 \alpha$ cross-talk pathway regulates heme synthesis in hepatic cells ${ }^{18,19}$. Whether Rev-erb- $\alpha$ interacts with Ppargc- $1 \alpha$ in muscle and whether Rev-erb- $\alpha$ controls skeletal muscle oxidative capacity has not yet been investigated. Here we find through loss- and gain-of-function experiments, including pharmacological activation, that Rev-erb- $\alpha$ plays a key role in regulating the oxidative capacity of the muscle and exercise endurance, and thus it emerges as a potential target to improve muscle function.

\footnotetext{
1 Institut Pasteur de Lille, Lille, France. ${ }^{2}$ Institut National de la Santé et de la Recherche Médicale Unité Mixte de Recherche 1011 'Nuclear Receptors, Cardiovascular Diseases and Diabetes', Lille, France. ${ }^{3}$ Faculté des Sciences Pharmaceutiques et Biologiques et Faculté de Médecine, Université Lille Nord de France, Lille, France. ${ }^{4}$ Université du Droit et de la Santé de Lille, Lille, France. ${ }^{5}$ European Genomic Institute for Diabetes, Lille, France. ${ }^{6}$ Department of Molecular Therapeutics, The Scripps Research Institute, Jupiter, Florida, USA. 7 Département de Physiologie Equipe d'Accueil 4484, Faculté de Médecine, Université Lille Nord de France, Lille, France. ${ }^{8}$ School for Nutrition, Toxicology and Metabolism, Department of Human Biology and Department of Human Movement Sciences, Maastricht University Medical Center, Maastricht, The Netherlands. ${ }^{9}$ These authors contributed equally to this work. Correspondence should be addressed to H.D. (helene.duez@pasteur-lille.fr) or B.S. (bart.staels@pasteur-lille.fr).
} 

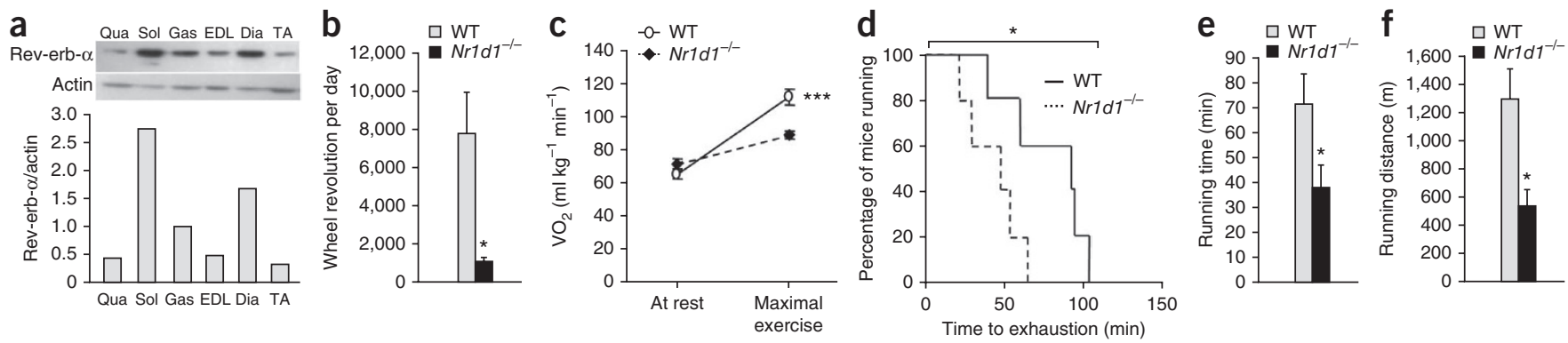

Figure $1 \mathrm{Nr} 1 \mathrm{d1}^{-/-}$mice have reduced voluntary activity and exercise performance. (a) Western blot analysis of Rev-erb- $\alpha$ protein levels in mouse muscles; actin was used as control. Qua, quadriceps; Sol, soleus; Gas, gastrocnemius; EDL, extensor digitorum longus; Dia, diaphragm; TA, tibialis anterior ( $n=7$ per group). (b) Wheel voluntary activity of $N r 1 d 1^{-l-}$ mice compared to WT mice ( $n=5$ per genotype). (c) Basal (at rest) and maximal aerobic capacity $\left(\mathrm{VO}_{2}\right)$ during a progressive treadmill test to exhaustion in an enclosed single-lane treadmill ( $n=9$ or 10 per genotype). (d) Endurance capacity of $\mathrm{Nr}_{\mathrm{d}} \mathrm{I}^{-/-}$mice compared to WT mice ( $n=6$ per genotype). (e,f) Running time (e) and distance (f) until exhaustion in endurance exercise ( $n=6$ per genotype). Data are expressed as means \pm s.e.m. ${ }^{*} P<0.05,{ }^{*} * *<0.001$ by unpaired $t$-test (a-c, e,f) and by log-rank Mantel-Cox test (d).

\section{RESULTS}

\section{Nr1d1 $1^{-l-}$ mice have lower exercise capacity}

Rev-erb- $\alpha$ expression is markedly higher in oxidative compared to more glycolytic muscles (Fig. 1a). Notably, its expression is higher in soleus and gastrocnemius muscle upon exercise training (Supplementary Fig. 1a). Thus, we explored whether Rev-erb- $\alpha$ has a role in skeletal muscle oxidative capacity and exercise capacity. $\mathrm{Nr} 1 \mathrm{~d} 1^{-/-}$mice showed significantly less spontaneous locomotor activity in a free-wheel exercise regimen compared to wild-type (WT) littermates (Fig. 1b).

We next assessed basal $\left(\mathrm{VO}_{2 \mathrm{~b}}\right)$ and maximal $\left(\mathrm{VO}_{2 \max }\right)$ oxygen consumption, which reflect aerobic capacity, by submitting $\mathrm{Nr} 1 \mathrm{~d} 1^{-/-}$ and WT mice to a forced progressive treadmill exercise. $\mathrm{VO}_{2 \mathrm{~b}}$ measured at rest was not significantly different between the two genotypes, whereas $\mathrm{VO}_{2 \max }$ measured at exhaustion was significantly lower in $\mathrm{Nr}_{\mathrm{d}} \mathrm{d}^{-/-}$mice (Fig. 1c), resulting in a $>60 \%$ reduction in aerobic capacity during exercise. In a standard endurance exercise test performed at $70 \%$ of their respective $\mathrm{VO}_{2 \max }, 50 \%$ of $\mathrm{Nr} 1 \mathrm{~d} 1^{-/-}$ mice, compared to only $20 \%$ of the WT mice, stopped running within $50 \mathrm{~min}$, which indicates their inability to sustain a long-lasting exercise (Fig. 1d). In this setting, $N r 1 d 1^{-/-}$mice ran for a significantly shorter time and distance than their WT littermates (Fig. 1e,f).

\section{Rev-erb- $\alpha$ controls muscle mitochondrial content and function}

We assessed the role of Rev-erb- $\alpha$ in the control of mitochondrial number and function in vivo (Fig. 2). Mitochondrial DNA content was $\sim 40 \%$ lower in skeletal muscle from $\mathrm{Nr} 1 \mathrm{~d} 1^{-/-}$mice compared to WT littermates (Fig. 2a), suggesting that Rev-erb- $\alpha$ is involved in regulating skeletal muscle mitochondrial content. Accordingly, expression of genes encoding subunits of the mitochondrial electron transport respiratory chain, such as NADH dehydrogenase 1, a subunit of complex I, and cytochrome $c$ oxidase 1 and cytochrome $c$ oxidase 2, two subunits of complex IV, was lower in soleus and

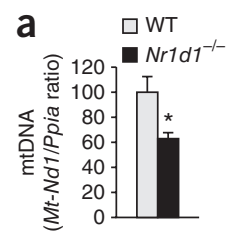

b

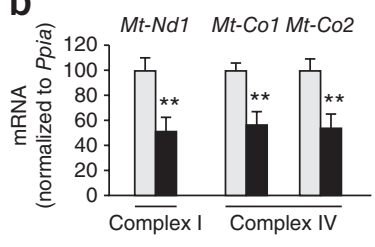

C

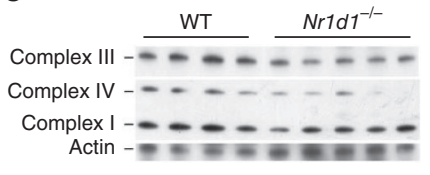

f

e

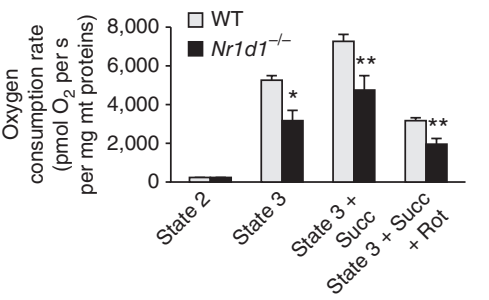

d
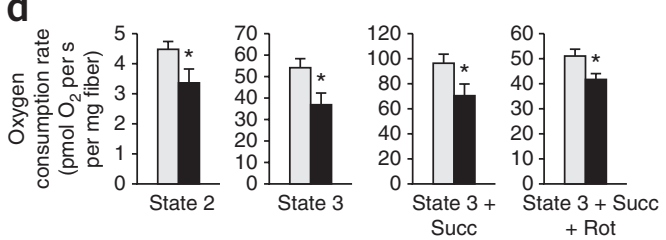

h

g
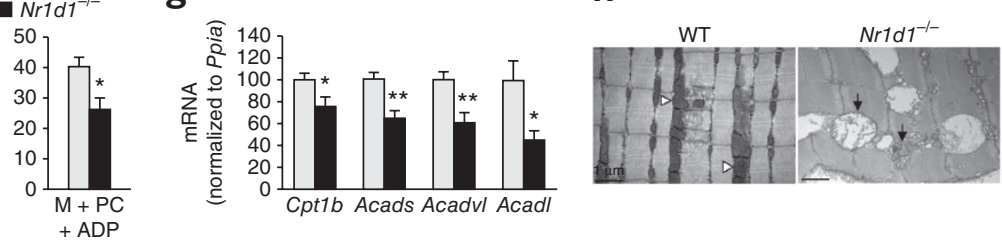

Figure 2 Rev-erb- $\alpha$ modulates mitochondrial content and function. (a) Mitochondrial DNA (mtDNA) content ( $n=6$ per genotype). Mt-Nd1, the gene encoding mitochondrial NADH dehydrogenase 1 . (b) RT-qPCR analysis of mitochondrial respiratory chain subunit genes in soleus muscle ( $n=7$ per genotype). Mt-Co1, mitochondrial cytochrome c oxidase 2 gene; Mt-Co2, mitochondrial cytochrome $c$ oxidase 2 gene. (c) Western blot analysis of mitochondrial complexes in soleus muscle from $\mathrm{Nr}_{1} d 1^{-1-}$ and WT mice ( $n=4$ or 5 per genotype). (d) Mitochondrial respiration in permeabilized soleus muscle fiber from $\mathrm{Nr} 1 d 1^{-/-}$and WT mice ( $n=7$ per genotype). Succ, succinate; Rot, rotenone. (e) Mitochondrial respiration from isolated muscle mitochondria ( $n=5$ per genotype). (f) Mitochondrial fatty acid $\beta$-oxidation-dependent respiration in isolated permeabilized soleus muscle fibers from $N r 1 d 1^{-l-}$ and WT mice ( $n=6$ per genotype). (g) Skeletal muscle (soleus) expression of genes encoding proteins involved in fatty acid oxidation ( $n=7$ per genotype). (h) Electron microscopy analysis of muscle from $\mathrm{Nr} 1 \mathrm{~d} 1^{-/}$and WT mice. Black arrows, swollen, less dense mitochondria; white arrowheads, normal mitochondria. Representative images from $n=5$ mice per genotype. Scale bar, $1 \mu \mathrm{m}$. Black, Nr1d1-l- mice; light gray, WT mice. Data are expressed as means \pm s.e.m. ${ }^{*} P<0.05,{ }^{*} P<0.01$ by unpaired $t$-test. 
a

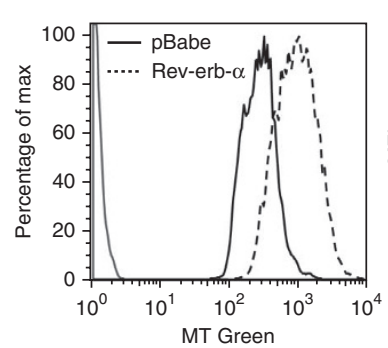

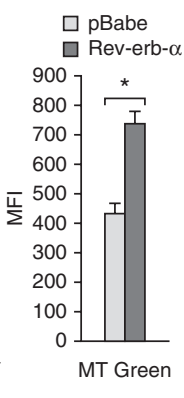

b

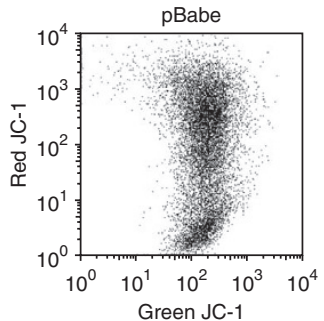

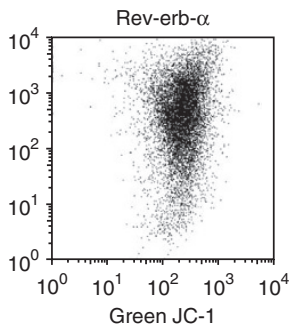

$\square$ pBabe

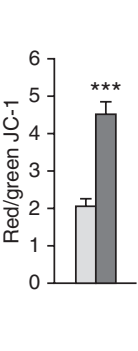

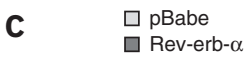

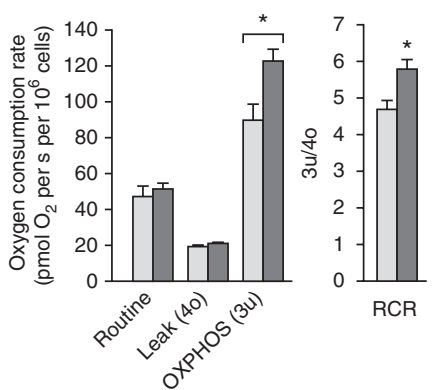

Figure 3 Rev-erb- $\alpha$ modulates mitochondrial respiration. (a) Mitochondria content in C2C12 cells infected with REV-ERB or control ( $p B a b e)$ retrovirus by flow cytometry analysis of MitoTracker (MT) Green staining (left, representative histogram; right, mean fluorescence intensity $(\mathrm{MFI})$ ) ( $n=6$ per condition). (b) Functional mitochondria content by flow cytometry analysis of JC-1 (left and middle) and red/green JC-1 (the high-low mitochondrial membrane potential) MFI ratio (right) ( $n=6$ per condition). (c) Oxygen consumption in REV-ERB- $\alpha$ and control pBabe cells ( $n=5$ per condition). (d) RT-qPCR analysis of fatty acid oxidation gene expression in differentiated C2C12 cells infected with REV-ERB- $\alpha$ or control ( $p B a b e$ ) retrovirus ( $n=6$ per group). Data are expressed as means \pm s.e.m. ${ }^{*} P<0.05, * * * P<0.001$ by unpaired $t$-test.

quadriceps muscle from $\mathrm{Nr} 1 d 1^{-/-}$mice compared to WT mice (Fig. 2b and Supplementary Fig. 1b). In addition, relative protein amounts of the mitochondrial oxidative phosphorylation complexes were lower in muscle from $\mathrm{Nr} 1 d 1^{-1-}$ mice compared to WT mice (Fig. 2c and Supplementary Fig. 1c). Moreover, glutamate-malate-stimulated (state 2) respiration was lower in isolated fibers from $\mathrm{Nr} 1 \mathrm{d1}^{-/-}$mice compared to WT mice, in line with the reduced mitochondrial content (Fig. 2d). Mitochondrial oxidative capacity was impaired in muscle from $\mathrm{Nr}_{1} d 1^{-/-}$mice, as attested by a significantly lower ADP-driven glutamate-malate (state 3 ) respiration rate in saponinpermeabilized fibers isolated from $N r 1 d 1^{-1-}$ compared to WT mice (Fig. 2d). The lower respiration upon addition of succinate and rotenone demonstrates a reduced capacity of the entire chain rather than a deficiency in a specific complex. This was further underscored by the significantly lower respiration rate observed when comparing equal amounts of isolated mitochondria (Fig. 2e), illustrating not only less mitochondrial content but also lower respiratory chain function of isolated mitochondria from $\mathrm{Nr} 1 \mathrm{~d} 1^{-/-}$compared to WT mice.

Although gene expression analysis of fiber type markers suggested a switch toward a more glycolytic profile (expression of the genes encoding tropomyosin 3, a marker of oxidative type I fiber, and myosin heavy chain IIa and IIx, markers of mostly oxidative fibers, is lower in soleus and quadriceps muscle from $N r 1 d 1^{-/-}$mice compared to WT mice (data not shown)), specific type I, type IIa and type IIb immunostaining did not reveal any significant changes between the two genotypes (Supplementary Fig. 1d). In addition, expression of $M b$ (the gene encoding myoglobin) and vascularization, assessed by CD31 immunostaining on soleus muscle sections, was similar between the two genotypes (Supplementary Fig. 5d,e).

To study whether Rev-erb- $\alpha$ regulates mitochondrial function in a cell-autonomous manner, we stably infected C2C12 muscle cells with a REV-ERB- $\alpha$-coding retrovirus. Staining with MitoTracker Green, a marker of mitochondria content, was higher in cells overexpressing REV-ERB- $\alpha$ compared with those infected with a control vector (Fig. 3a). Notably, the red-to-green ratio of JC-1 fluorochrome, an indicator of membrane potential, was also higher in $\mathrm{C} 2 \mathrm{C} 12$ cells overexpressing REV-ERB- $\alpha$ compared to cells infected with an empty $\mathrm{pBabe}$ control retrovirus, suggesting increased mitochondrial activity (Fig. 3b). REV-ERB- $\alpha$ expression enhanced the maximal respiratory capacity through enhanced coupled ATP-producing oxidative phosphorylation, as illustrated by higher-state $3 \mathrm{u}$ respiration rate and respiratory control ratio (RCR, OXPHOS/leak), whereas the uncoupling proton leakage remained unchanged (Fig. 3c). Conversely, Nr1d1 silencing resulted in lower mitochondrial respiration compared to control shRNA-infected cells (Supplementary Fig. 2a), as well as the quantity of total (MitoTracker Green) and functional (MitoTracker Red) mitochondria (Supplementary Fig. 2b) in differentiated C2C12 cells. Analysis of mitochondrial fatty acid oxidation in permeabilized fibers of muscle from $\mathrm{Nr} 1 d 1^{-/-}$mice revealed compromised oxygen consumption in the presence of palmitoyl-L-carnitine plus malate alone and in the presence of ADP (Fig. 2f). In parallel, the expression of genes encoding enzymes of fatty acid $\beta$-oxidation, notably carnitine palmitoyltransferase 1B (Cpt1b) and (very) long chain (Acadvl and Acadl) and short chain (Acads) acyl-CoA dehydrogenases, was lower in skeletal muscle from $\mathrm{Nr} 1 d 1^{-/-}$compared with WT mice (Fig. $2 \mathrm{~g}$ and Supplementary Fig. 3a), whereas REV-ERB- $\alpha$ retrovirus-infected C2C12 cells had a mirror phenotype (that is, higher Acadvl, Acadl and Acads expression, and thus a higher acyl-CoA dehydrogenase expression) compared to control cells infected with an empty control pBabe retrovirus (Fig. 3d). These results indicate that Rev-erb- $\alpha$ modulates fatty acid $\beta$-oxidation-driven generation of reducing equivalents to feed into the electron transport chain in vitro and ex vivo in skeletal muscle. Together, these results demonstrate that Rev-erb- $\alpha$ regulates muscle cell mitochondrial content and function.

Electron microscopy analysis of muscle sections revealed a slight misalignment of $\mathrm{Z}$ lines, the presence of vacuolated fibers and the presence of abnormal, swollen and less dense mitochondria in muscle sections from $\mathrm{Nr} 1 \mathrm{~d} 1^{-/-}$mice compared to WT littermates (Fig. 2h and Supplementary Fig. 4), which indicate a severe skeletal muscle phenotype and mitochondrial dysfunction in the $\mathrm{Nr} 1 \mathrm{d1^{-1- }}$ mice. The repair process, assessed by the presence of centrocellular nuclei (Supplementary Fig. 5a shows that the nuclei are localized at the periphery of the fibers, confirming the absence of regeneration) and the absence of change in the expression of Pax7 and Myf5 (Supplementary Fig. 5b), was not different between $\mathrm{Nr} 1 \mathrm{~d} 1^{-/-}$mice and WT littermates. In line with this, immunofluorescence staining of Pax7 indicated its localization at the boundary of the myofiber (Supplementary Fig. 5c), which implies the presence of quiescent 

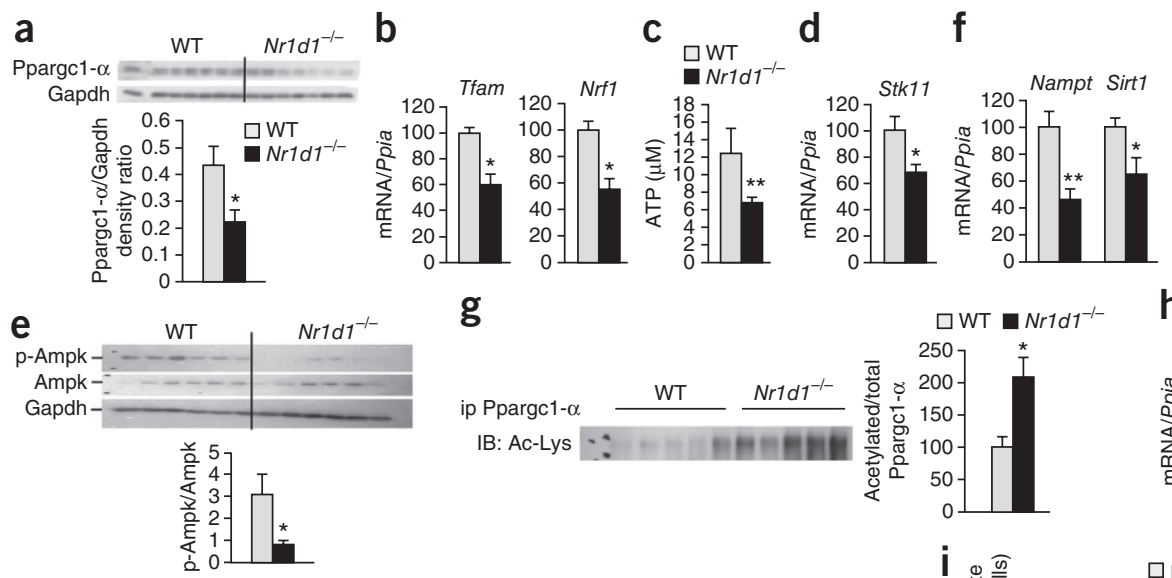

$\mathrm{g}$
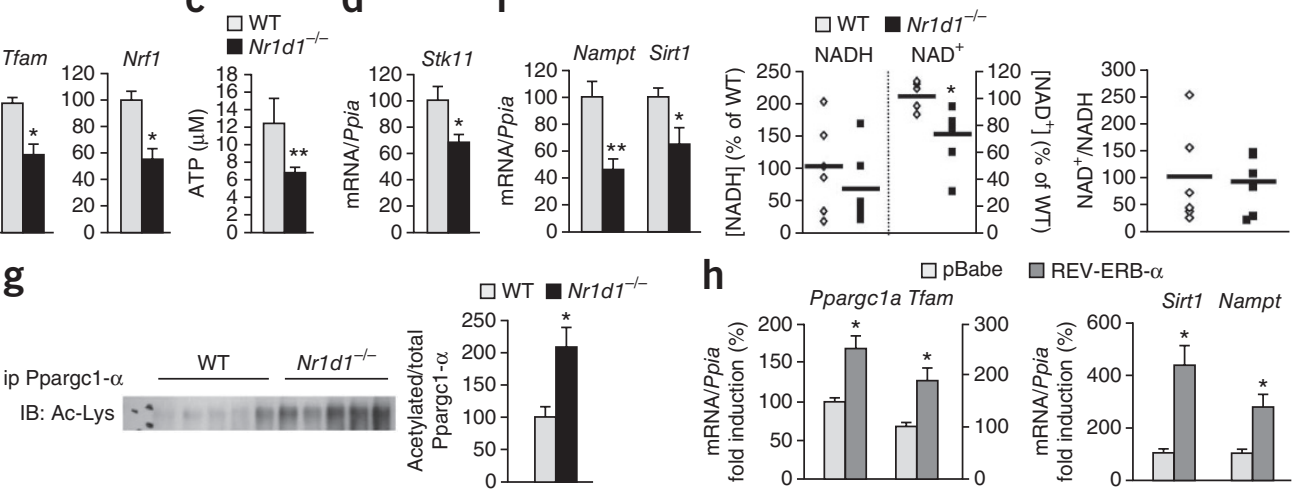

\section{h}

$\square$ pBabe $\square$ REV-ERB- $\alpha$
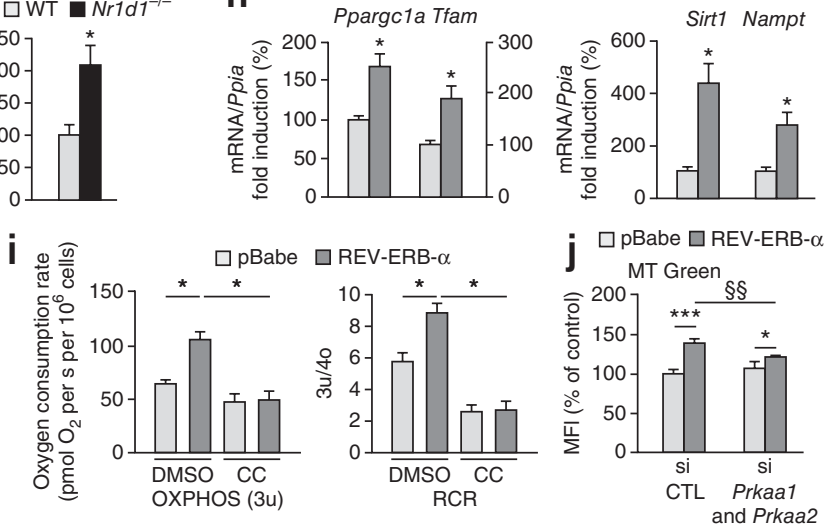

Figure 4 Rev-erb- $\alpha$ modulates mitochondrial biogenesis by interfering with Ampk-Sirt1-Ppargc-1 $\alpha$ signaling. (a-g) Relative protein amounts of Ppargc-1 $\alpha$ (a), mRNA concentrations of Tfam and nuclear respiratory factor 1 (Nrf1) (b), cellular ATP concentrations (c), Stk11 mRNA concentrations (d), western blot analysis of Ampk phosphorylation (e), Nampt and Sirt 1 mRNA and NAD ${ }^{+}$and NADH cellular concentrations (f) and relative amounts of acetylated Ppargc- $1 \alpha$ protein $(\mathrm{g})$ in soleus muscle from NrId1 $1^{-/-}$and WT mice ( $n=7$ per genotype). Black, NrId1 $1^{-/-}$mice; light gray, WT mice (a-g). IB, immunoblot. (h) Ppargcla, Tfam, Sirt1 and Nampt gene expression in C2C12 cells infected with REV-ERB- $\alpha$ or control ( $p B a b e)$ retrovirus ( $n=6$ per group). Light gray, empty pBabe retrovirus-infected cells; dark gray, REV-ERB- $\alpha$-overexpressing cells ( $\mathbf{h}-\mathbf{j})$. (i) OXPHOS (3u) mitochondrial respiration and RCR in absence or presence of the Ampk phosphorylation inhibitor C compound (CC) in C2C12 cells infected with REV-ERB- $\alpha$ or control ( $p B$ abe) retrovirus ( $n=6$ per condition). (j) Mitochondria content in $\mathrm{C} 2 \mathrm{C} 12$ cells infected with REV-ERB- $\alpha$ or control ( $p$ Babe) retrovirus, transfected with siRNA to reduce Prkaa1 and Prkaa2 expression or a scramble control siRNA/MitoTracker Green MFI ( $n=3$ per condition). Results are expressed as means \pm s.e.m. ${ }^{*} P<0.05$, ${ }^{* *} P<0.01$, and $* * * P<0.001$, $\S P<0.01$ by unpaired $t$-test.

satellite cells located on the border of myofibers, which are similar in the two genotypes.

\section{Rev-erb- $\alpha$ increases skeletal muscle mitochondrial biogenesis}

We assessed whether Rev-erb- $\alpha$ regulates mitochondrial biogenesis in loss- and gain-of-function settings (Fig. 4). Both mRNA ( 56\%) and protein $(\sim 50 \%)$ amounts of Ppargc-1 $\alpha$, which has a pivotal role in mitochondrial biogenesis, were lower in soleus and quadriceps muscle from $\mathrm{Nr} 1 \mathrm{d1}^{-/-}$mice as compared to WT mice (Fig. 4a and Supplementary Fig. 3b,d). Consistently, the expression of Tfam and Nrf1, encoding mitochondrial transcription factor A and nuclear respiratory factor 1, respectively, two transcription factors that are involved in mitochondrial biogenesis, was lower in $\mathrm{Nr} 1 \mathrm{d1^{-/- }}$ mice compared to WT mice (Fig. 4b). By contrast, REV-ERB- $\alpha$ overexpression resulted in higher Ppargcla and Tfam expression in C2C12 cells compared to cells infected with an empty pBabe control retrovirus (Fig. 4h).

As a functional reflection of impaired mitochondrial electron transport chain activity, ATP concentrations were significantly lower in muscle from $\mathrm{Nr}_{\mathrm{d} 11^{-/}}$mice compared to WT mice (Fig. 4c). Ampk, a 'fuel gauge' activated by liver kinase B1 (Lkb1, also known as serinethreonine kinase 11 or Stk11) when the AMP/ATP ratio increases, induces Sirt1-dependent deacetylation of Ppargc-1 $\alpha$ and expression of nicotinamide phosphoribosyltransferase (Nampt), the rate-limiting enzyme in the synthesis of the Sirt 1 cofactor $\mathrm{NAD}^{+}$, thus affecting mitochondrial and lipid oxidation genes ${ }^{20}$. Of note, $S t k 11$ gene expression (Fig. 4d and Supplementary Fig. 3d), Ampk phosphorylation (Fig. 4e) and activity illustrated by the p-Acac/Acac (phosphorylated acetylCoA carboxylase/total acetyl-CoA carboxylase) ratio (Supplementary Fig. 3c) and Nampt gene expression (Fig. 4f) were lower in muscle from $\mathrm{Nr}_{1} \mathrm{d1}^{-/-}$mice compared to WT mice. Concentrations of $\mathrm{NAD}^{+}$ and $\mathrm{NADH}$, the reducing equivalent produced by fatty acid oxidation, were lower in skeletal muscle from $\mathrm{Nr} 1 \mathrm{d1}^{-/-}$mice compared to that of their WT littermates (Fig. 4f). Moreover, we observed significantly less Sirt1 expression in skeletal muscle from $\mathrm{Nr} 1 \mathrm{~d} 1^{-/-}$compared to WT mice (Fig. 4f and Supplementary Fig. 3d), and SIRT1 activity was blunted, as attested by increased Ppargc- $1 \alpha$ acetylation (Fig. 4g). Conversely, Sirt1 and Nampt expression was induced in REV-ERB- $\alpha$-overexpressing C2C12 cells (Fig. 4h) and accompanied by significantly improved mitochondrial respiration, an effect that was fully blocked by the addition of the C compound, an inhibitor of Ampk phosphorylation (Fig. 4i). Consistent with this, siRNA knockdown of genes encoding Ampk (Prkaa1 and Prkaa2) prevented the increase in mitochondrial content upon REV-ERB- $\alpha$ overexpression (Fig. 4j), whereas Ampk activation by 5-aminoimidazole-4-carboxamide ribonucleotide (AICAR) increased mitochondrial number in cells stably transduced with Nr1d1 shRNA but not to the same extent as in control cells stably transduced with control shRNA (Supplementary Fig. 2c). Together, these data indicate that Rev-erb- $\alpha$ regulates skeletal muscle mitochondria biogenesis through modulation of the Lkb1-Ampk-Sirt1-Ppargc-1 $\alpha$ pathway.

\section{Rev-erb- $\alpha$ deficiency induces skeletal muscle autophagy}

We next explored whether Rev-erb- $\alpha$ also modulates mitochondrial degradation. Autophagy is a process mediating the selective clearance of cytoplasmic components, such as damaged mitochondria, that could otherwise become deleterious. Autophagy is a self-digestion process occurring through the formation of a vesicle (nucleation) that expands to become an autophagosome, which then engulfs cellular components and directs them to the lysosome for degradation. Expression of the genes encoding Ulk1, a protein of the initiation complex implicated in vesicle formation, and Beclin1, a protein of 
a

$\square$ WT

- $\mathrm{Nr}_{1 \mathrm{~d} 1^{-1-}}$

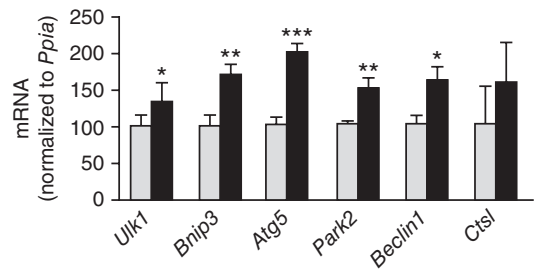

e
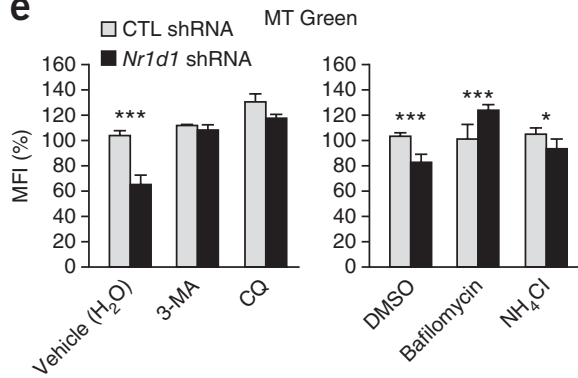

b

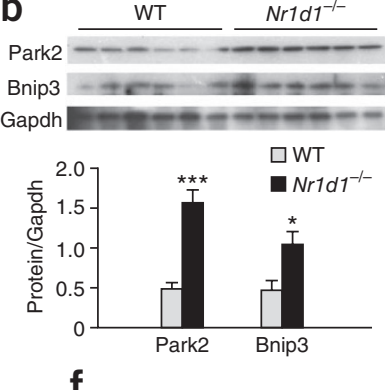

f
C

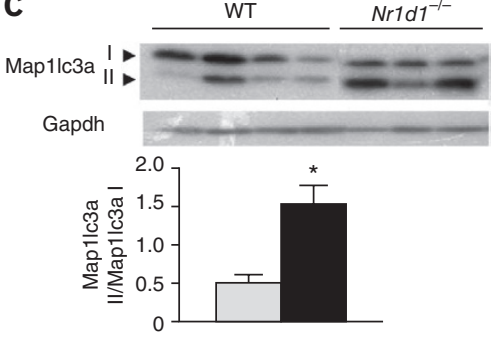

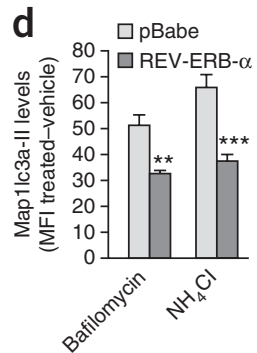

g

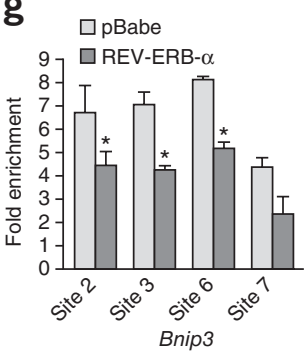

H3K27Ac
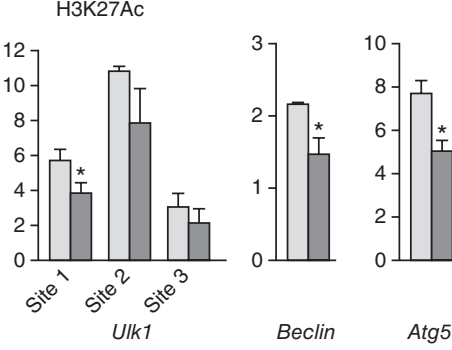

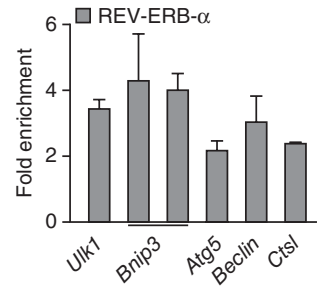

Figure 5 Rev-erb- $\alpha$ modulates skeletal muscle autophagy. (a) RT-qPCR analysis of autophagy gene expression in soleus from $\mathrm{Nr}_{1 \mathrm{~d} 1^{-/}}$and WT littermates ( $n=7$ per genotype). (b) Western blot analysis and their quantifications of soleus muscle Park2 and Bnip3 proteins in Nr1d1-/- mice compared to WT littermates. (c) Western blot analysis and their quantifications of Map1lc3a-I and Map1lc3a-II protein in soleus from NrId $1^{-1-}$ and WT mice ( $n=3$ or 4 per genotype). (d) Flow cytometry quantification of Map1lc3a-II protein amounts in C2C12 cells infected with REV-ERB- $\alpha$ or control ( $p B a b e)$ retrovirus and treated with lysosome inhibitors ( $50 \mathrm{nM}$ bafilomycin or $25 \mathrm{mM} \mathrm{NH}_{4} \mathrm{Cl}$ ) or their respective vehicle after $16 \mathrm{~h}$ serum deprivation, expressed as MFI (lysosomal inhibitors minus vehicle) ( $n=6$ per condition). (e) Mitochondria content in cells that have been stably transduced using an Nr1d1 shRNA-encoding retrovirus or control (CTL) shRNA

h $\square$ pBabe H3K9Ac

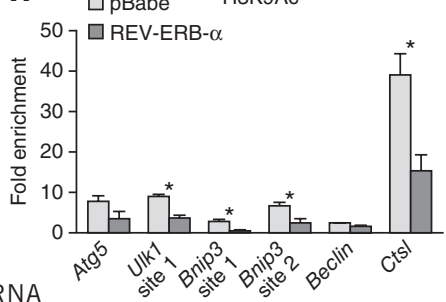
and treated with $5 \mathrm{mM}$ 3-methyl adenine (3-MA) or $50 \mu \mathrm{M}$ chloroquine (CQ), or $100 \mathrm{nM}$ bafilomycin or $25 \mathrm{mM} \mathrm{NH}_{4} \mathrm{Cl}$, or their respective vehicle, as measured by specific MitoTracker (MT) Green flow cytometry MFI ( $n=6$ per condition). (f) Rev-erb- $\alpha$ binding to regulatory regions of the indicated autophagy genes measured by ChIP-qPCR ( $n=3$ independent experiments). (g,h) ChIP-qPCR examining the REV-ERB- $\alpha$ binding regions from e for changes in $\mathrm{H} 3 \mathrm{~K} 27$ and $\mathrm{H} 3 \mathrm{~K} 9$ acetylation ( $n=3$ independent experiments). ( $\mathbf{f}-\mathbf{h})$ ChIP experiments were conducted on C2C12 cells infected with REV-ERB- $\alpha$ or control (pBabe) retrovirus. Data are expressed as means \pm s.e.m. ${ }^{*} P<0.05,{ }^{* *} P<0.01,{ }^{* * *} P<0.001$ by unpaired $t$-test.

the nucleation complex, as well as autophagy-related 5 (Atg5) and Bnip3, which are responsible for vesicle elongation and autophagosome formation, and the lysosomal enzymes cathepsin L (Ctsl) and ATPase6v1b2 was higher in skeletal muscle of $\mathrm{Nr}_{1} \mathrm{d1}^{-1-}$ compared to WT mice (Fig. 5a,b) and lower in REV-ERB- $\alpha$ retrovirus-infected C2C12 cells compared to control cells infected with an empty pBabe control retrovirus (Supplementary Fig. 6). Rev-erb- $\alpha$ also regulated gene and protein expression of Parkin (also known as Park2), a protein specifically involved in mitochondrial clearance ${ }^{21}$ (Fig. $5 \mathbf{b}$ and Supplementary Fig. 6). The functional increase of autophagy was illustrated by the maturation of microtubule-associated protein 1 light chain $3 \alpha$ (Map1lc3a-I, also known as LC3) to its lipidated form, Map1lc3a-II, a marker of ongoing autophagy associated with the autophagosome membrane (Fig. 5c). Moreover, treatment with the lysosome inhibitors bafilomycin and $\mathrm{NH}_{4} \mathrm{Cl}$, which block the fusion of the lysosome with mature autophagosomes that subsequently accumulate, resulted in a smaller increase of Map1lc3a-II expression in REV-ERB- $\alpha$-overexpressing C2C12 cells than in treated control (pBabe) cells (Fig. 5d). This indicates that autophagy flux is lower when REV-ERB- $\alpha$ is overexpressed. Conversely, the number of mitochondria was lower after Nr1d1 silencing in C2C12 cells, and addition of the autophagy blockers 3-methyl adenine and chloroquine or the lysosome inhibitors bafilomycin and $\mathrm{NH}_{4} \mathrm{Cl}$ prevented this decrease (Fig. 5e). These results suggest that Rev-erb- $\alpha$ deficiency results in an increased autophagy flux, thus contributing to the lower mitochondria number.
To gain further mechanistic insight, we examined the distribution of Rev-erb- $\alpha$ binding sites in the vicinity of autophagy genes, assessed using chromatin immunoprecipitation (ChIP) sequencing data ${ }^{17}$, and overlaid it with epigenetic marks obtained in $\mathrm{C} 2 \mathrm{C} 12$ myotubes ${ }^{22}$. We reasoned that intense transcriptional activity at these marks may increase the likelihood of Rev-erb- $\alpha$ binding to these locations. Primers for ChIP-quantitative PCR (qPCR) targeting these regions were then designed to assess REV-ERB- $\alpha$ binding and changes in acetylation marks in REV-ERB- $\alpha$-expressing C2C12 cells. We observed an enrichment of Rev-erb- $\alpha$ binding in the regulatory regions of several autophagy genes (Fig. 5f), which was associated with decreased acetylation at histone 3 Lys27 (H3K27) (Fig. 5g) and Lys9 (H3K9) (Fig. 5h).

\section{Rev-erb- $\alpha$ activation improves muscle mitochondrial function}

Next, we determined the effect of pharmacological activation of Rev-erb- $\alpha$ on exercise capacity, which we achieved by treating mice with the synthetic ligand SR9009 (ref. 12). Notably, in an endurance exercise test, mice treated with SR9009 ran significantly longer, both in time and in distance, than mice treated with vehicle (Fig. 6a).

Incubation of $\mathrm{C} 2 \mathrm{C} 12$ cells with two different Rev-erb agonists, SR9009 and SR9011, increased the number of total (MitoTracker Green) and active (MitoTracker Red) mitochondria (Fig. 6b). Finally, skeletal muscle-specific Rev-erb- $\alpha$ overexpression in mice significantly improved mitochondrial function, as attested by a significant increase in glutamate-malate-stimulated and ADP-driven 
Figure 6 Rev-erb- $\alpha$ overexpression or pharmacological activity improves mitochondrial function and exercise capacity. (a) Running distance and time until exhaustion in endurance exercise in mice treated with SR9009 (100 mg per kg body weight for $30 \mathrm{~d})(n=6$ per group). (b) Mitochondria content in $\mathrm{C} 2 \mathrm{C} 12$ cells treated with SR9009 (5 $\mu \mathrm{M})$, SR9011 (5 $\mu \mathrm{M})$ or vehicle as shown by representative bar graph of flow cytometry green MitoTracker (top) and red MitoTracker (bottom) staining ( $n=4$ per condition). (c) Mitochondrial respiration in permeabilized fiber isolated from tibialis anterior muscle from mice intramuscularly injected with a Rev-erb- $\alpha$-expressing adeno-associated virus (AAV) vector (AAV-Rev-erb- $\alpha$ ) ( $n=4$ per group). Data are expressed as means \pm s.e.m. ${ }^{*} P<0.05,{ }^{*} P<0.01$ by unpaired $t$-test. a

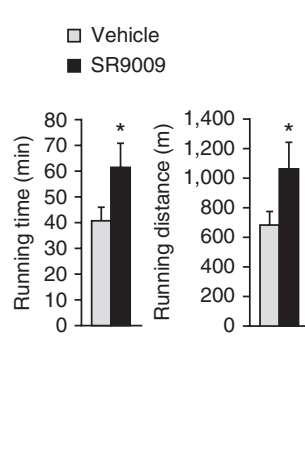

b

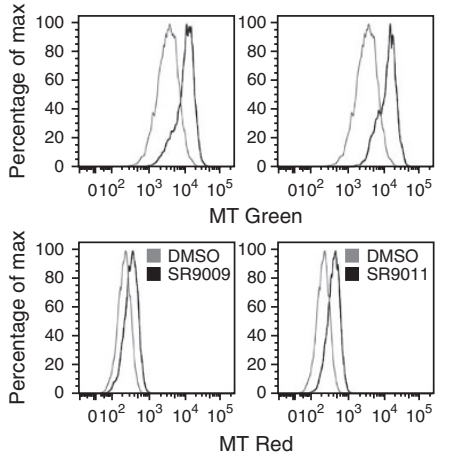

C

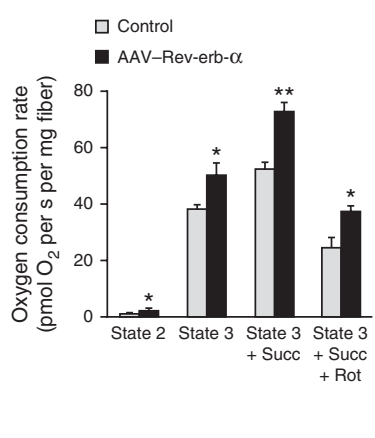

respiration in the absence and presence of succinate in permeabilized fibers (Fig. 6c). Together, these data indicate that enhancement of Rev-erb- $\alpha$ expression, activity or both exerts beneficial direct effects on skeletal muscle to improve mitochondrial respiration and exercise capacity.

\section{DISCUSSION}

Our results from both gain- and loss-of-function experiments identify Rev-erb- $\alpha$ as a physiological regulator of muscle mitochondrial content and oxidative function. This is supported by several observations. First, Rev-erb- $\alpha$ is preferentially expressed in more oxidative muscles, such as soleus muscle, and $\mathrm{Nr} 1 d 1^{-/-}$mice have notably altered exercise capacity associated with a marked decrease in mitochondrial content and function, the presence of swollen mitochondria and abundant vacuoles within the fibers. We observed similar alterations upon knockdown of Nr1d1 in differentiated C2C12 myotubes (lower mitochondrial content and impaired mitochondrial function). By contrast, pharmacological activation or skeletal muscle-specific Rev-erb- $\alpha$ overexpression in vivo and in vitro in $\mathrm{C} 2 \mathrm{C} 12$ cells resulted in the opposite phenotype, highlighting the fact that Rev-erb- $\alpha$ exerts a direct action on skeletal muscle cells. Second, our data indicate that Rev-erb- $\alpha$ controls mitochondrial biogenesis and respiration through the Lkb1-Ampk-Sirt1-Ppargc-1 $\alpha$ signaling pathway. Finally, we show that skeletal muscle Rev-erb- $\alpha$ regulates several genes involved in different steps of the autophagy process, including genes more specifically dedicated to mitophagy. Together, these data support the concept that Rev-erb- $\alpha$ acts through a two-pronged mechanism, involving both biogenesis of new mitochondria and clearance of defective mitochondria. Thus, when Rev-erb- $\alpha$ is activated, there is an increase in mitochondrial number and a better control of autophagic flux, allowing for a higher oxidative capacity.

The regulation of the Lkb1-Ampk-Sirt1-Ppargc-1 $\alpha$ pathway by Rev-erb- $\alpha$ provides a molecular mechanism whereby Rev-erb- $\alpha$ controls mitochondrial biogenesis and function. Ampk and Sirt1 are crucial in the metabolic flexibility that allows skeletal muscle to switch to lipid oxidation during fasting and exercise. Deficient Ampk activity in $\mathrm{Nr} 1 \mathrm{d1}^{-/-}$mice is associated with impaired Sirt1-mediated Ppargc- $1 \alpha$ deacetylation and the ensuing attenuated induction of mitochondrial fatty acid oxidation gene expression and reduced exercise capacity ${ }^{20,23}$. Likewise, Ppargc- $1 \alpha$ acetylation is higher and its expression diminishes in Rev-erb- $\alpha$ deficiency, which may contribute to the reduced number of mitochondria, lower expression of transcription factors important for mitochondrial function, such as Tfam, and altered electron transport chain activity. In addition, expression of genes encoding fatty acid $\beta$-oxidation enzymes as well as palmitate-induced mitochondrial respiration is compromised in the absence of Rev-erb- $\alpha$. A considerable deactivation of the Lkb1-AmpkSirt1-Ppargc- $1 \alpha$ pathway when Rev-erb- $\alpha$ is deficient is further shown by defective Ampk activation, reduced $\mathrm{NAD}^{+}$concentrations and markedly altered Sirt 1 and Nampt expression. Moreover, siRNAmediated or C compound-mediated inhibition of Ampk activity, which blocks the stimulatory effect of REV-ERB- $\alpha$ overexpression on mitochondrial respiration, demonstrates that Rev-erb- $\alpha$-mediated improvement of mitochondrial respiration requires active Ampk. Of note, in $N r 1 d 1^{-/-}$mice, Ampk phosphorylation is not induced even though ATP concentrations are low. Binding of AMP increases the ability of other kinases to phosphorylate and activate the Ampk- $\alpha$ subunit. Lkb1, expressed in skeletal muscle, is a major upstream kinase that phosphorylates and activates Ampk, and Stk11-deficiency results in blunted Ampk activation, decreased Ppargc1a expression, reduced exercise capacity and compromised mitochondrial activity ${ }^{24,25}$, a phenotype similar to the one observed in the $\mathrm{Nr} 1 \mathrm{~d} 1^{-/-}$mice. Our results also indicate that mitochondria are damaged and mitochondrial oxygen consumption is reduced in muscle from $\mathrm{Nr} 1 \mathrm{d1^{-/ }}$ mice, whereas skeletal muscle-specific Rev-erb- $\alpha$ overexpression improves mitochondrial respiration. Moreover, treatment of mice with a synthetic Rev-erb- $\alpha$ agonist increases oxygen consumption ${ }^{12}$. Notably, and in contrast to other transcriptional regulators, such as $\mathrm{Ppar}-\beta / \delta$ (ref. 2) and Ppargc-1 $\alpha$ (refs. 1,6), Rev-erb- $\alpha$ modulates skeletal muscle oxidative capacity without inducing a fiber type switch, suggesting a disconnection between both phenomena upon Rev-erb- $\alpha$ deficiency. Together, these data support a prominent role for Rev-erb- $\alpha$ in skeletal muscle mitochondria function.

Autophagy is a dynamic self-digestion process that ensures the selective clearance of damaged organelles or aggregated macromolecules, which is a particularly important mechanism in differentiated cells such as myotubes ${ }^{26-28}$. Our data demonstrate that Rev-erb- $\alpha$ exerts a tight control on this pathway by regulating several genes involved in vesicle nucleation and expansion, autophagosome formation and lysosomal enzymatic activities. The conversion of Map1lc3a-I to its lipidated form, Map1lc3a-II, is a hallmark of autophagy ${ }^{29}$. The rate of maturation to Map1lc3a-II was elevated in the absence of Rev-erb- $\alpha$, whereas autophagy flux is decreased by REV-ERB $\alpha$ overexpression. Of note, Rev-erb- $\alpha$ represses genes encoding proteins that trigger mitophagy, such as Park2, a cytosolic E3 ubiquitin ligase that translocates to depolarized mitochondria to induce mitophagy, thereby maintaining a pool of functioning mitochondria and limiting oxidative damage ${ }^{21}$. Likewise, Rev-erb- $\alpha$ downregulates Ulk1, which not only participates in the initiation complex but also may play an important part in triggering mitophagy ${ }^{30}$. Ulk1 deficiency indeed 
results in accumulation of defective mitochondria in mature red blood cells ${ }^{31}$. Finally, we demonstrate that autophagy blockade by autophagy or lysosome inhibitors reverses the effect of $\mathrm{Nr} 1 \mathrm{~d} 1$ knockdown on total mitochondria number.

Autophagy is also a survival mechanism by which cells produce energy in times of nutrient paucity. One of the most potent inducers of autophagy is Ampk, which directly phosphorylates Ulk1 and, simultaneously, turns off signaling of mTORC1, an inhibitor of autophagy $26,28,32$. However, neither Ampk (which is downregulated in the absence of Rev-erb- $\alpha$ ) nor mTOR, whose signaling is not regulated by Rev-erb- $\alpha$ (data not shown), is likely to mediate Rev-erb- $\alpha$ 's action on autophagy. Another potent autophagy inducer, Sirt1 (ref. 33), is also downregulated in the absence of Rev-erb- $\alpha$, again excluding the possibility that Sirt1 has a role in the observed phenotype. Together, these data indicate that Rev-erb- $\alpha$ bypasses these regulators and represses autophagy genes directly, probably by binding the DNA in their regulatory regions. Indeed, our ChIP-qPCR data confirmed Rev-erb- $\alpha$ binding enrichment in the regulatory regions of autophagy genes. This was accompanied by a modification of epigenetic marks at these sites, as indicated by decreased H3K27 and H3K9 acetylation, which is consistent with the repressive role of Rev-erb- $\alpha$ on gene transcription.

Rev-erb- $\alpha$ is a component of the circadian clock, which allows synchronization of internal rhythms to daily environmental cues ${ }^{34}$. Skeletal muscle has circadian rhythmicity of gene expression ${ }^{35,36}$, and the clock components Clock and Bmal1 (brain and muscle Arnt-like 1) have been shown to participate in the maintenance of skeletal muscle function $^{37}$. The mRNA concentrations of the clock genes are altered in skeletal muscle from $\mathrm{Nr} 1 \mathrm{~d} 1^{-/-}$mice (Supplementary Fig. 7a), and REV-ERB- $\alpha$ overexpression in synchronized C2C12 cells leads to an altered circadian expression pattern of Ppargc1a (Supplementary Fig. 7b). Pharmacological activation of Rev-erb- $\alpha$ alters the circadian rhythms of Cpt1b and Ppargc1a in skeletal muscle ${ }^{12}$. Consequently, in addition to the direct action of Rev-erb- $\alpha$ on autophagy genes and mitochondrial biogenesis and function, $\mathrm{Nr} 1 \mathrm{~d} 1$ deletion or overexpression that causes disturbed circadian rhythmicity may contribute to the observed phenotype. In conclusion, Rev-erb- $\alpha$ is a major physiological regulator of mitochondrial content and oxidative function. Thus, pharmacological activation of Rev-erb- $\alpha$ may be a promising approach for the treatment of skeletal muscle diseases with compromised exercise capacity.

\section{METHODS}

Methods and any associated references are available in the online version of the paper.

\section{Note: Supplementary information is available in the online version of the paper.}

\section{ACKNOWLEDGMENTS}

This research was supported by a Marie Curie International Reintegration Grant (FP7) (to H.D.), the European Commission (FP7) consortium Eurhythdia (to B.S.), Région Nord Pas-de-Calais/Fonds Européen de Développement Régional (to B.S.), a Contrat de Projet Etat-Région 'starting grant' (to H.D.), the European Genomic Institute for Diabetes (EGID, ANR-10-LABX-46) (to B.S.), an unrestricted Instituts Thématiques Multi-Organismes/Astra Zeneca grant (to B.S.), a joint Société Francophone du Diabète/Merck Sharp \& Dohme research fellowship (to H.D.), a research grant from the European Foundation for the Study of Diabetes/Lilly (to H.D.), US National Institutes of Health grants (MH093429 and DK080201) (to T.P.B.), a National Research Service Award (DK088499) (to L.A.S.) and a VICI research grant for innovative research from the Netherlands Organization for Scientific Research (918.96.618) (to P.S.). B.S. receives support from the Institut Universitaire de France.

\section{AUTHOR CONTRIBUTIONS}

E.W., Y. Sebti, B.S. and H.D. were responsible for the study design, data analysis and interpretation and wrote the manuscript. E.W., Y. Sebti, L.A.S., C.D., S.L., C.P., S.D., G.S. and R.N. performed the experiments and data analysis. J.E., P.L., M.K.C.H., P.S. and T.P.B. were involved in data analysis. Y. Shin and T.M.K. were involved in Rev-erb- $\alpha$ ligand chemistry.

\section{COMPETING FINANCIAL INTERESTS}

The authors declare no competing financial interests.

Reprints and permissions information is available online at http://www.nature.com/ reprints/index.html.

1. Lin, J. et al. Transcriptional co-activator PGC-1 $\alpha$ drives the formation of slow-twitch muscle fibres. Nature 418, 797-801 (2002).

2. Schuler, M. et al. PGC1 $\alpha$ expression is controlled in skeletal muscles by PPAR $\beta$ whose ablation results in fiber-type switching, obesity, and type 2 diabetes. Cell Metab. 4, 407-414 (2006).

3. Narkar, V.A. et al. Exercise and PGC-1 $\alpha$-independent synchronization of type muscle metabolism and vasculature by ERRgamma. Cell Metab. 13, 283-293 (2011).

4. Zechner, C. et al. Total skeletal muscle PGC-1 deficiency uncouples mitochondrial derangements from fiber type determination and insulin sensitivity. Cell Metab. 12 633-642 (2010).

5. Yamamoto, H. et al. NCoR1 is a conserved physiological modulator of muscle mass and oxidative function. Cell 147, 827-839 (2011).

6. Handschin, C. et al. Skeletal muscle fiber-type switching, exercise intolerance, and myopathy in PGC- $1 \alpha$ muscle-specific knock-out animals. J. Biol. Chem. 282 30014-30021 (2007).

7. Leone, T.C. et al. PGC- $1 \alpha$ deficiency causes multi-system energy metabolic derangements: muscle dysfunction, abnormal weight control and hepatic steatosis. PLOS Biol. 3, e101 (2005).

8. Duez, H. \& Staels, B. Nuclear receptors linking circadian rhythms and cardiometabolic control. Arterioscler. Thromb. Vasc. Biol. 30, 1529-1534 (2010).

9. Duez, H. et al. Regulation of bile acid synthesis by the nuclear receptor Rev-erbo. Gastroenterology 135, 689-698 (2008).

10. Yin, L. et al. Rev-erbo, a heme sensor that coordinates metabolic and circadian pathways. Science 318, 1786-1789 (2007).

11. Cho, H. et al. Regulation of circadian behaviour and metabolism by REV-ERB- $\alpha$ and REV-ERB- $\beta$. Nature 485, 123-127 (2012).

12. Solt, L.A. et al. Regulation of circadian behaviour and metabolism by synthetic REV-ERB agonists. Nature 485, 62-68 (2012).

13. Bugge, A. et al. Rev-erbo and Rev-erb $\beta$ coordinately protect the circadian clock and normal metabolic function. Genes Dev. 26, 657-667 (2012).

14. Fontaine, C. et al. The orphan nuclear receptor Rev-Erbo is a peroxisome proliferator activated receptor (PPAR) $\gamma$ target gene and promotes PPAR $\gamma$-induced adipocyte differentiation. J. Biol. Chem. 278, 37672-37680 (2003).

15. Wang, J. \& Lazar, M.A. Bifunctional role of Rev-erb $\alpha$ in adipocyte differentiation. Mol. Cell Biol. 28, 2213-2220 (2008).

16. Fontaine, C. et al. The nuclear receptor Rev-erb $\alpha$ is a liver X receptor (LXR) target gene driving a negative feedback loop on select LXR-induced pathways in human macrophages. Mol. Endocrinol. 22, 1797-1811 (2008).

17. Feng, D. et al. A circadian rhythm orchestrated by histone deacetylase 3 controls hepatic lipid metabolism. Science 331, 1315-1319 (2011).

18. Wu, N., Yin, L., Hanniman, E.A., Joshi, S. \& Lazar, M.A. Negative feedback maintenance of heme homeostasis by its receptor, Rev-erb $\alpha$. Genes Dev. 23 2201-2209 (2009).

19. Estall, J.L. et al. PGC- $1 \alpha$ negatively regulates hepatic FGF21 expression by modulating the heme/Rev-Erbo axis. Proc. Natl. Acad. Sci. USA 106 22510-22515 (2009).

20. Cantó, C. et al. Interdependence of AMPK and SIRT1 for metabolic adaptation to fasting and exercise in skeletal muscle. Cell Metab. 11, 213-219 (2010).

21. Narendra, D., Tanaka, A., Suen, D.F. \& Youle, R.J. Parkin is recruited selectively to impaired mitochondria and promotes their autophagy. J. Cell Biol. 183, 795-803 (2008).

22. Asp, P. et al. Genome-wide remodeling of the epigenetic landscape during myogenic differentiation. Proc. Natl. Acad. Sci. 108, E149-E158 (2011).

23. Fujii, N. et al. Role of AMP-activated protein kinase in exercise capacity, whole body glucose homeostasis, and glucose transport in skeletal muscle -insight from analysis of a transgenic mouse model. Diabetes Res. Clin. Pract. 77 (suppl. 1), S92-S98 (2007)

24. Koh, H.J. et al. Skeletal muscle-selective knockout of LKB1 increases insulin sensitivity, improves glucose homeostasis, and decreases TRB3. Mol. Cell Biol. 26 , 8217-8227 (2006).

25. Thomson, D.M. et al. Skeletal muscle dysfunction in muscle-specific LKB1 knockout mice. J. Appl. Physiol. 108, 1775-1785 (2010).

26. Mihaylova, M.M. \& Shaw, R.J. The AMPK signalling pathway coordinates cell growth, autophagy and metabolism. Nat. Cell Biol. 13, 1016-1023 (2011).

27. Rabinowitz, J.D. \& White, E. Autophagy and metabolism. Science 330, 1344-1348 (2010). 


\section{ARTICLES}

28. Kroemer, G., Marino, G. \& Levine, B. Autophagy and the integrated stress response. Mol. Cell 40, 280-293 (2010)

29. Kabeya, Y. et al. LC3, a mammalian homologue of yeast Apg8p, is localized in autophagosome membranes after processing. EMBO J. 19, 5720-5728 (2000).

30. Joo, J.H. et al. Hsp90-Cdc37 chaperone complex regulates Ulk1- and Atg13mediated mitophagy. Mol. Cell 43, 572-585 (2011).

31. Kundu, M. et al. Ulk1 plays a critical role in the autophagic clearance of mitochondria and ribosomes during reticulocyte maturation. Blood 112, 1493-1502 (2008).

32. Egan, D.F. et al. Phosphorylation of ULK1 (hATG1) by AMP-activated protein kinase connects energy sensing to mitophagy. Science 331, 456-461 (2011).
33. Lee, I.H. et al. A role for the NAD-dependent deacetylase Sirt1 in the regulation of autophagy. Proc. Natl. Acad. Sci. USA 105, 3374-3379 (2008).

34. Bass, J. Circadian topology of metabolism. Nature 491, 348-356 (2012).

35. McCarthy, J.J. et al. Identification of the circadian transcriptome in adult mouse skeletal muscle. Physiol. Genomics 31, 86-95 (2007).

36. Miller, B.H. et al. Circadian and CLOCK-controlled regulation of the mouse transcriptome and cell proliferation. Proc. Natl. Acad. Sci. USA 104, 3342-3347 (2007).

37. Andrews, J.L. et al. CLOCK and BMAL1 regulate MyoD and are necessary for maintenance of skeletal muscle phenotype and function. Proc. Natl. Acad. Sci. USA 107, 19090-19095 (2010). 


\section{ONLINE METHODS}

Mice. We used $\mathrm{Nr}_{1} \mathrm{~d}^{-/-}$mice $^{38}$ and their wild-type (WT) littermates $\left(\mathrm{Nr}_{\mathrm{d}} \mathrm{d} \mathrm{1}^{+/+}\right.$ mice). Mice were housed in a $12 \mathrm{~h}-12 \mathrm{~h}$ light-dark cycle and allowed ad libitum access to food and water. They received a regular chow diet. Mice were killed by cervical dislocation, and skeletal muscles were snap-frozen in liquid nitrogen and stored at $-80^{\circ} \mathrm{C}$ until RNA and protein isolation and histological staining. Rev-erb- $\alpha$ deficiency in mice was verified by qPCR analysis of skeletal muscle gene expression of $\mathrm{Nr} 1 \mathrm{dl}$ land its known target gene Arntl, also known as Bmall (Supplementary Fig. 8a).

For Rev-erb- $\alpha$ overexpression, we cloned the coding sequence of Rev-erb- $\alpha$ in front of a muscle creatine kinase (MCK) promoter, allowing muscle-specific expression, and introduced a 1/2 adeno-associated virus (AAV) vector (Sirion Biotech, Germany). We injected $2.1 \times 10^{10}$ infectious particles intramuscularly into the tibialis anterior muscle using the tibialis anterior muscle of the contralateral limb as control. For pharmacological activation, SR9009 was administered intraperitoneally at $100 \mathrm{mpk}$ for $30 \mathrm{~d}$ as previously described ${ }^{12}$. Control mice were injected with vehicle ( $15 \%$ cremophor in sterile water).

Maximal exercise stress test and endurance capacity. Two days before the experiment, mice were acclimatized to a single lane treadmill by performing a $10 \mathrm{~m} \mathrm{~min}^{-1} \mathrm{run}$. The day of the exercise stress test, mice were placed into the treadmill enclosed in a metabolic chamber connected to an oxygen sensor (Oxymax, Columbus Instruments, Columbus, Ohio). We measured basal oxygen consumption $\left(\mathrm{VO}_{2 \mathrm{~b}}\right)$ after a 30-min resting period; then, mice were encouraged to run on the treadmill at $10 \mathrm{~m} \mathrm{~min}^{-1}$ and $0 \%$ incline. Every $3 \mathrm{~min}$, the treadmill speed was incremented by $4 \mathrm{~m} \mathrm{~min}^{-1}$ until the mice reached exhaustion to determine their maximal $\mathrm{VO}_{2}\left(\mathrm{VO}_{2 \max }\right)$. The speed at which $\mathrm{VO}_{2 \max }$ was obtained was considered the maximal running speed $\left(\mathrm{V}_{\max }\right)$. One week later, we tested the mice for their endurance capacity. After a 6-min run at $30 \%$ of their maximal running speed, the treadmill speed was set at $70 \%$ of the $\mathrm{VO}_{2 \max }$. The experiment was stopped when mice stayed for $5 \mathrm{~s}$ continuously on the electrical grid. Time to exhaustion and total running distance were determined.

Daily wheel running activity. To record daily running wheel behavior, we placed the mice into individual cages containing running wheels for 3 weeks (Campden, Phymep, Paris). Wheel revolution was recorded daily during the last 2 weeks and averaged.

Training. We examined Rev-erb- $\alpha$ expression in control (untrained) and exercised mice. Mice were trained for 8 weeks, $5 \mathrm{~d}$ per week, $1-2 \mathrm{~h}$ per day at a starting speed of $8 \mathrm{~m} \mathrm{~min}^{-1}$, which was increased up to $16 \mathrm{~m} \mathrm{~min}^{-1}$ during the last 4 weeks.

Mouse care and use were performed according to approved institutional guidelines, and all experimental procedures were approved by the relevant ethic committees (Comité déthique en expérimentation animale Nord-Pas-De-Calais and The Scripps Research Institute Florida Campus Institutional Animal Care and Use Committee). We used male mice for all experiments.

Cell culture. We cultured C2C12 myoblasts in Dulbecco's modified Eagle's medium (DMEM; $4.5 \mathrm{~g} \mathrm{l}^{-1} \mathrm{D}$-glucose; Gibco) supplemented with $10 \% \mathrm{FBS}$ and $1 \%$ gentamycin. Myogenic differentiation into myotubes was induced when cells reached $80 \%$ confluency by adding DMEM supplemented with $2 \%$ horse serum and $1 \%$ gentamycin at $37^{\circ} \mathrm{C}$ in a humidified incubator under $5 \% \mathrm{CO}_{2}$ for $2-5 \mathrm{~d}$. As indicated in Figure 6, we added SR9009 or SR9011 $(5 \mu \mathrm{M})$ to the medium $1 \mathrm{~d}$ before differentiation and for the length of the differentiation period $(8 \mathrm{~d})$.

Serum shock. We assessed circadian gene expression patterns in cells after synchronization by a 2 -h horse serum shock on near-confluent cells ${ }^{39}$. After $2 \mathrm{~h}$, the medium was changed to $2 \%$ serum-containing medium as above.

Retroviral production and infection. We cultured Phoenix Eco cells (Orbigen) in DMEM containing $10 \% \mathrm{FBS}$ and $1 \%$ gentamycin at $37^{\circ} \mathrm{C}$ under standard culture conditions. To generate cell lines constitutively overexpressing REV-ERB- $\alpha$, we inserted the coding sequence of human NR1D1 in the pBabe retrovirus plasmid (Addgene) using the BamHI-SalII sites to generate pBabe-REV-ERB- $\alpha$. We used the empty vector (pBabe) as control. To downregulate Nr1d1 expression, we inserted the Nr1d1 shRNA sequence in psilencer 5.1-U6 Retro (Ambion) using the BamH1 and HindIII sites. Phoenix cells $\left(100,000\right.$ per $\left.\mathrm{cm}^{2}\right)$ were transfected with the pBabe plasmid constructs $(20 \mu \mathrm{g})$ using the cationic lipid RPR 120535B as previously described ${ }^{40}$. C2C12 cells were infected with the supernatant from $\mathrm{pBabe}$ or pBabe-REV-ERB- $\alpha$, and control (CTL) shRNA or Nr1d1 shRNA and puromycin-resistant infected cells were used within $15 \mathrm{~d}$ after infection. We verified NR1D1 overexpression by RT-qPCR on REV-ERB- $\alpha$ retrovirus-infected $\mathrm{C} 2 \mathrm{C} 12$ cells compared to $\mathrm{pBabe}$ retrovirus-infected control cells (Supplementary Fig. 8b). We verified REV-ERB- $\alpha$ nuclear localization by western blot analysis (Supplementary Fig. 8c), and we verified its repressive transcriptional activity by transient transfection on a consensus RevDR2 site in $\mathrm{C} 2 \mathrm{C} 12$ cells infected with REV-ERB- $\alpha$ retrovirus compared to those infected with pBabe retrovirus, as well as to noninfected $\mathrm{C} 2 \mathrm{C} 12$ cells after transfection of a pSG5Rev-erb- $\alpha$ expression plasmid as control (Supplementary Fig. 8d). Nrld1 downregulation was verified by qPCR analysis of Nrld1 mRNA on Nr1d1 shRNA-transduced C2C12 cells compared with control cells (Supplementary Fig. 8e).

Determination of cellular respiration. $\mathrm{C} 2 \mathrm{C} 12$ cells $\left(1 \times 10^{6}\right.$ cells ml $\left.^{-1}\right)$ suspended in cell culture medium (RPMI $+10 \% \mathrm{FCS}$ ) were placed into the chambers of the $\mathrm{O} 2 \mathrm{~K}$ oxygraph operating at $37^{\circ} \mathrm{C}$. Routine respiration was measured $20 \mathrm{~min}$ later. Then, $2 \mu \mathrm{g} \mathrm{ml}^{-1}$ oligomycin was injected into the chambers to obtain the oligomycin-inhibited leak rate of respiration (4o, Leak, 'L'), or uncoupled respiration. Finally, pulses of carbonyl cyanide-p-trifluoromethoxyphenylhydrazone (FCCP) $(1 \mu \mathrm{M})$ were added into the chambers until maximal oxygen consumption was reached ( $3 \mathrm{u}, \mathrm{OXPHOS}$, ' $\mathrm{P}$ '). It represents the maximal respiratory capacity. The respiratory control ratio (RCR), or the coupled oxidative phosphorylation, is expressed as $3 \mathrm{u} / 4 \mathrm{o}$ ratio.

Oxygen consumption on permeabilized soleus fibers. After cervical dislocation, soleus or tibialis anterior muscles were excised and placed into a Petri dish containing ice-cold biopsy preservation solution (BIOPS), and permeabilized fibers were prepared as previously described ${ }^{41}$. We placed fibers (3-6 mg wet weight) into the $\mathrm{O} 2 \mathrm{~K}$ oxygraph chambers (Oroboros Instruments, Innsbruck, Austria). In the first chamber, we added glutamate $(10 \mathrm{mM})$ and malate $(2 \mathrm{mM})$ to obtain state 2 respiration. Then, we injected $2.5 \mathrm{mM}$ ADP into the chamber to measure ADP-coupled oxygen consumption (state 3). Further addition of succinate $(10 \mathrm{mM})$ allowed estimation of the entire OXPHOS capacity. Finally, complex I and complex III were inhibited with rotenone $(0.5 \mu \mathrm{M})$ and antimycin A $(2.5 \mu \mathrm{M})$, respectively. In the second chamber, we added palmitoyl-carnitine $(5$ or $20 \mu \mathrm{M})$ and malate $(2 \mathrm{mM})$. After stabilization, coupled respiration was obtained with $2.5 \mathrm{mM}$ ADP. Addition of exogenous cytochrome $c(10 \mu \mathrm{M})$ was done in all experiments to test external membrane integrity. Experiments were performed at $25^{\circ} \mathrm{C}$.

Muscle mitochondria isolation. We cut muscles into small pieces and placed them into a trypsin-EDTA solution for $15 \mathrm{~min}$ at $4{ }^{\circ} \mathrm{C}$. Samples were rinsed with mitochondrial isolation buffer (in mM: sucrose 300, TES 5, EGTA 0.2; $\mathrm{pH}$ 7.2) and homogenized with a glass tissue grinder. After centrifugation at $800 \mathrm{~g}$ for $7 \mathrm{~min}$, supernatant was collected and spun twice at $8,800 \mathrm{~g}$. The final mitochondrial pellet was suspended into respiration medium Mitomed2 and mitochondria $(150 \mu \mathrm{g})$ were placed into the oxygraph chambers. Substrates and protocols were as described for permeabilized fiber respiration.

Mitochondria quantity and function. Quantification of mtDNA copy number We isolated mitochondrial DNA (mtDNA) from mouse muscles after digestion with Proteinase $\mathrm{K}\left(100 \mu \mathrm{g} \mathrm{ml}^{-1}\right)$ by phenol/chloroform extraction. Relative amounts of nuclear DNA and mtDNA were determined by quantitative real-time PCR. We selected NADH dehydrogenase 1-coding gene for quantification of mtDNA and Ppia (also known as cyclophilin) for nuclear DNA quantification.

MitoTracker-FACS quantification. REV-ERB- $\alpha$-overexpressing, Nr1d1 shRNA-transduced cells and their respective control cells were washed with PBS, trypsinized and incubated at $37^{\circ} \mathrm{C}$ for $20 \mathrm{~min}$ with $100 \mathrm{nM}$ MitoTracker Green FM and Red FM dyes (Molecular Probes). MitoTracker Green probe preferentially accumulates in mitochondria, allowing estimation of mitochondrial quantity. MitoTracker Red probe is a red fluorescent dye that stains mitochondria 
in living cells and its accumulation is dependent on the membrane potential (Molecular Probes). Samples were washed 3 times in PBS and subjected to flow cytometric analysis on a FACSCalibur apparatus (Becton Dickinson, San Jose, California).

ATP assay. We measured ATP concentrations using a commercially available kit (EnzyLight ATP Assay Kit, Bioassay Systems, Hayward, California, USA) following the manufacturer's instructions.

NAD assay. We measured $\mathrm{NAD}^{+}$and NADH concentrations using a commercially available kit (Biovision Research Products, Mountain View, California, USA) following the manufacturer's instructions.

Quantitative PCR. We isolated total RNA from tissues by guanidinium thiocyanate/phenol/chloroform extraction ${ }^{42}$ and from $\mathrm{C} 2 \mathrm{C} 12$ cells using the Trizol reagent (Invitrogen). Isolated RNA was reverse transcribed into cDNA using commercially available reagents (Superscript II kit, Applied Bioscience). We performed quantitative PCR (qPCR) with the Brilliant III SYBR Green QPCR Master Mix (Agilent) and specific primers following manufacturer's instructions and using a Mx3005 apparatus (Agilent). Gene expression was normalized to cyclophilin and expressed as indicated in the legends to figures. A list of specific primers is available in Supplementary Table 1.

Antibodies and immunoblotting. Proteins extracted from muscle biopsies or cells were separated by SDS-PAGE and we performed immunoblot analyses according to standard procedures. Proteins were transferred onto PVDF membranes and immunoblot analyses were carried out using antibodies directed against p-AMPK (Thr172) (1:1,000, Cell Signaling Technology 2535) and AMPK (1:1,000, Cell Signaling Technology 2532), Ppargc-1 $\alpha$ (1:500, Santa-Cruz Biotechnology, sc-13067), Gapdh (1:500, Santa-Cruz Biotechnology, sc-25778), actin (1:1,000, Santa-Cruz Biotechnology sc-1616), Bnip3 and Map1lc3a (1:1,000, Abcam38621 and Abcam51520, respectively), Park2 (1:1,000, Millipore ab9244), Acac (1:1,000, Cell Signaling 3662), p-Acac (S79) (1:1,000, Cell Signaling 3661), OXPHOS (1:1,000, MitoSciences InVitrogen, iv 458099), Rev-erb- $\alpha$ (1:1,000, Perseus Proteomix PP-A8740A-00) following the manufacturer's instructions.

Ppargc-1 $\alpha$ acetylation assay. We analyzed Ppargc- $1 \alpha$ acetylation in quadriceps muscle by immunoprecipitation of Ppargc1- $\alpha$ from $500 \mu \mathrm{g}$ of protein extract with antibodies to Ppargc- $1 \alpha$ (Santa Cruz, sc-13067, $2 \mu$ g per sample) followed by western blot analysis using antibodies to acetyl-lysine (1:2,000, Cell Signaling 9441).

Electron microscopy analysis of muscle sections. We examined ultrastructural muscle morphology using transmission electron microscopy. To this end, muscle tissue blocks were fixed in $2.5 \%$ glutaraldehyde in $0.1 \mathrm{M}$ phosphate buffer (pH 7.4). Post-fixation was performed in $1 \% \mathrm{OsO}_{4}$ in $0.1 \mathrm{M}$ cacodylate buffer (pH 7.4) supplemented with $1.5 \% \mathrm{~K}_{4}\left[\mathrm{Fe}(\mathrm{CN})_{6}\right]$. Subsequently, samples were dehydrated and embedded in epon. Ultrathin sections were examined using a Philips CM100 electron microscope.

Immunofluorescence assay. Frozen cross-sections of muscle were fixed with acetone and incubated with antibodies directed to CD31 (1:100, BD Biosciences, BD557355), Pax7 (1:20, Developmental Studies Hybridoma Bank, PAX7), fiber types (1:25, Developmental Studies Hybridoma Bank, A4.840), and laminin (1:50, Sigma L9393). After incubation with the appropriate fluorescent-labeled secondary antibodies (goat anti-rabbit IgG conjugated to AlexaFluor 555 for CD31, goat anti-mouse IgG1 conjugated to AlexaFluor 488 for Pax7, goat antirabbit IgG conjugated to AlexaFluor 350 for laminin and goat anti-mouse IgM conjugated to AlexaFluor 488 for A4.840, all from InVitrogen/Molecular Probes) and DAPI (30 nM, Invitrogen) for nuclei, sections were mounted in Mowiol. Images were captured with a Nikon E800 fluorescence microscope ${ }^{43}$.

Flow cytometry Map1lc3a analysis. REV-ERB- $\alpha$-overexpressing and control cells were seeded in 6-well plates and serum-starved in presence or absence of Bafilomycin $(50 \mathrm{nM})$ or $\mathrm{NH}_{4} \mathrm{Cl}(25 \mathrm{mM})$ overnight at $37^{\circ} \mathrm{C}$.

Before staining with antibody to Map1lc3a (1:50, MBL International M152-3 clone 4E12), we fixed the cells with $4 \%$ paraformaldehyde for $15 \mathrm{~min}$ at room temperature, washed them in PBS and then permeabilized them with digitonin $\left(100 \mu \mathrm{g} \mathrm{ml}^{-1}\right)$ for $15 \mathrm{~min}$ at room temperature. Digitonin permeabilization allowed the extraction of the cytosolic form of Map1lc3a protein (Map1lc3a-I) and the specific detection of the lipidated Map1lc3a-membrane-associated fraction (Map1lc3a-II), which correlates with the number of autophagosomes ${ }^{44}$. Cells were finally incubated with Alexa Fluor 488-conjugated antibody to mouse IgG for 15 min (1:200, Invitrogen, A11001). We acquired sample signals using FACSCalibur (Becton Dickinson, San Jose, CA) and analyzed them using FlowJo software (Tree Star).

Chromatin immunoprecipitation. We performed ChIP-qPCR experiments as previously described ${ }^{45}$ with minor changes as follows. Differentiated C2C12 cells infected with the REV-ERB- $\alpha$ or control (pBabe) retrovirus were crosslinked in $1 \%$ formaldehyde for $10 \mathrm{~min}$ at room temperature. Nuclear extracts were prepared, and the chromatin was sonicated for $15 \mathrm{~min}$ using the Bioruptor (Diagenode). Chromatins were immunoprecipitated overnight at $4{ }^{\circ} \mathrm{C}$ with antibodies to Rev-erb- $\alpha$ (Cell Signaling Technology, 2124), H3K9Ac (Millipore, 17-658) or H3K27Ac (AbCam, ab4729), all at $3 \mu \mathrm{g}$ per sample, and then incubated for $4 \mathrm{~h}$ at $4{ }^{\circ} \mathrm{C}$ with protein $\mathrm{A}$ and protein $\mathrm{G}$ Dynal magnetic beads (Dynal Biotech, Norway) and tRNA $\left(10 \mu \mathrm{g} \mathrm{ml}^{-1}\right)$. Cross-linking was reversed overnight at $65^{\circ} \mathrm{C}$. DNA was purified using the QIAquick PCR purification kit (Qiagen) and was analyzed by quantitative PCR using the Brilliant III SYBR Green QPCR Master Mix (Agilent) using specific primers (Supplementary Table 2).

Statistical analyses. Values are means \pm s.e.m. of the indicated number of measurements. Statistical significance was determined using two-tailed unpaired Student's $t$-test with a significance of 0.05 or log-rank Mantel-Cox test.

38. Duez, H. et al. Regulation of bile acid synthesis by the nuclear receptor Reverbalpha. Gastroenterology 135, 689-698 (2008).

39. Nagoshi, E. et al. Circadian gene expression in individual fibroblasts: cellautonomous and self-sustained oscillators pass time to daughter cells. Cell 119, 693-705 (2004).

40. Raspé, E. et al. Identification of Rev-erb $\alpha$ as a physiological repressor of apoC-III gene transcription. J. Lipid Res. 43, 2172-2179 (2002).

41. Aragonés, J. et al. Deficency or inhibition of oxygen sensor Phd1 induces hypoxia tolerance by reprogramming basal metabolism. Nat. Genet. 40, 170-180 (2008).

42. Chomczynski, P. \& Sacchi, N. Single-step method of RNA isolation by acid guanidinium thiocyanate-phenol-chloroform extraction. Anal. Biochem. 162, 156-159 (1987).

43. Delhaas, T. et al. Steep increase in myonuclear domain size during infancy. Anat. Rec. 296, 192-197 (2013).

44. Kaminskyy, V. et al. A quantitative assay for the monitoring of autophagosome accumulation in different phases of the cell cycle. Autophagy 7, 83-90 (2011).

45. Eeckhoute, J., Lupien, M. \& Brown, M. Combining chromatin immunoprecipitation and oligonucleotide tiling arrays (ChIP-Chip) for functional genomic studies. Methods Mol. Biol. 556, 155-164 (2009). 